\title{
Attention Deficit Hyperactivity Disorder and Social Anxiety in İstanbul Heavy Metal Bar Patrons
}

\author{
Özalp Ekinci', Yasin Bez², Volkan Topçuoglu33, Serdar Nurmedow ${ }^{3}$ \\ ${ }^{1}$ Clinic of Child Psychitary, Antakya Child Care Home, Hatay, Turkey \\ ${ }^{2}$ Department of Psychiatry, Faculty of Medicine, Dicle Universty, Diyarbakır, Turkey \\ ${ }^{3}$ Department of Psychiatry, Faculty of Medicine, Marmara Universty, Istanbul, Turkey
}

\begin{abstract}
Objective: We aimed to examine the heavy metal bar patrons in Istanbul by means of self-reported questionnaires for psychiatric disorder symptoms.

Material and Methods: Seventy-one volunteers from 4 popular heavy metal bars were included to the study. The Beck Depression Inventory, the Liebowitz Social Anxiety Scale (LSAS), the Adult Attention Deficit Disorder/Attention Deficit and Hyperactivity Disorder (ADD/ADHD) Scale and the Michigan Alcoholism Screening Test (MAST) were administered to the participants.
\end{abstract}

Results: One fourth of the participants (25.4\%) were under high risk for a depressive episode (BDI>17), 22 (32.3\%) reported significant social anxiety (LSAS>30), and 41 (57.7\%) showed moderate ADHD symptoms (Adult ADD/ADHD scale: 20-59). According to BDI score participants who were under the risk for depression showed higher scores in Adult ADD/ADHD scale scores than that of participants who were not under a risk for depression ( $p=0.001$ for attention deficit; $p=0.003$ for hyperactivity; $p=0.002$ for impulsivity; $p=0.001$ for total score). In the study group, ADD/ADHD scale attention deficit score was positively correlated with the total fear, total avoidence and the total scores of LSAS $(r=.359 p<0.01 ; r=.332 p<0.01 ; r=.358$ $\mathrm{p}<0.01$, respectively).

Conclusion: Heavy metal bar patrons appear to be a particular social group with an increased risk of psychopathology.

Key Words: Heavy metal, music preference, bar, social anxiety, ADHD

Received: 03.11.2010

Accepted: 20.05.2011

\section{Introduction}

Although not widely studied, the heavy metal subculture appears to exist not only in Western countries, but also across the entire world. Whilst on tour in non-Western countries, most heavy metal musicians express great surprise at seeing huge crowds singing along to all of their songs. Indeed, the outlook, social styles, and habits of these fans do not seem to be distinctively different from ones in Western countries (1).

A number of previous studies have shown that a heavy metal music preference may be associated with an increased risk of drug abuse, academic failure, family problems, recklessness, impulsive behaviors, depression, and suicide (2). However, to the best our knowledge, all of these studies were conducted in Western countries. It is not known whether there are differences between Western and non-Western countries in the psychiatric profiles of individuals who prefer heavy metal music.

The question could be asked, "What is the second most common habit that the individuals from the heavy metal subculture share after listening to heavy metal music?" The answer would probably be that they go to bars and pubs which play this kind of music. Heavy metal bars differ from most other bars by the high volume of the music, the pervasiveness of beer drinking, and the darkness of the style of the places which all reflect the heavy metal culture itself. The people inside do not typically dance, in contrast to disco and dance bars, but head banging and/or joining in on the songs loudly is common. Although a handfull of studies focused on the psychosocial characteristics of people who frequently visit bar/pubs in general (3-6) heavy metal bar patrons, as a particular group, have not been studied previously.

Among the Islamic societies, there appears to be a negative attitude toward heavy metal subculture which includes the personel characteristics of wearing black clothes, leather jackets and skinny fit jeans and having long hair in men and also the social habits of visiting heavy metal bars and heavy metal concerts $(1,7,8)$. To our knowledge, no previous article examined the social acceptability of visiting heavy metal bars and the characteristics of heavy metal bars patrons in Turkey.

This study aims, by means of self-report questionnaires, to examine the young adults who commonly visit heavy metal bars, and their various psychiatric disorder symptoms. The two main reasons why the authors selected this population for this study are as follows:

1. There is a limited literature on heavy metal subculture in Western Countries. The characteristics of the heavy metal subculture in non-Western countries are, however, largely unknown. Istanbul is uniquely placed in the world in its mix of Western and Eastern cultural traditions. 
2. Heavy metal bars are particular social places for heavy metal fans. The individuals who regularly attend these places may have specific psychiatric and socio-demographic profiles.

\section{Material and Methods}

\section{Study design}

The research team made a detailed inquiry on the popular heavy metal bars in Istanbul. Both the scientific (Sciencedirect, Medline, Pubmed) and general web search engines (Google, Yahoo) were used in this process. Since no published article was found in scientific literature, the selection of populer heavy metal bars in Istanbul were based on the information of an international website "www.metaltravelguide.com". According to the website, a total of 12 heavy metal bars were present in Istanbul. Amongst these, four populer and highly rated bars were selected for the study. A research team contacted the chief bartenders of these bars and informed them about the research. For a period of 6 months, on Wednesday, Friday, Saturday nights, one member of the research team visited these bars. For the duration of 1 hour, at the entrance of the bars, the member of the research team briefly explained the research to the people entering the bar and asked for their participation in the study. From the 136 people who were invited to participate in the study seventy-one of them (52\%) accepted. The people who accepted were carefully instructed on how to fill out the study questionnaires. They were asked to fill out the questionnaires at home, not in the bar. They were also told not to fill out the forms when they were drinking alcohol or using drugs. For the individuals who accepted, appointments were made and the completed forms were collected within a one week period approximately.

\section{Study Measures}

\section{Beck Depression Inventory (BDI)}

The BDI is a scale developed by Beck in 1961 for assessing the depression risk and severity of depressive symptoms (9). It can be administered to both psychiatric patients and the general population. It is a self-report scale and consists of 21 Likert type items each scored between 0-3. The total score can be obtained simply by adding the scores for all items. The validity and reliability of the Turkish version of the BDI was demonstrated by Hisli in 1989 (10).

\section{Liebowitz Social Anxiety Scale (LSAS)}

The LSAS is a questionnaire developed by Liebowitz for the purpose of assessing the severity of fear and avoidance in social interactions and performance situations. The questionnaire includes 24 items, 11 assessing social situations and 13 assessing social performance situations. Administered by a clinician, the scale provides scores on 6 subscales, measuring the severity of fear in social situations, the severity of performance fear, the severity of social avoidance, the severity of performance avoidance, the severity of total fear, and the severity of total avoidance. The total score of the LSAS can be achieved by simply adding the total fear and total avoidance scores. A score of 30 on the LSAS has been reported to be the best balance of sensitivity and specificity for differentiating patients with social anxiety disorder from healthy controls (11). The validity and reliability of the Turkish version of the LSAS was demonstrated by Soykan et al. in 2003 (12).

Adult ADD/ADHD Diagnostic Screening and Rating Scale

The Adult Attention Deficit Disorder/Attention Deficit and Hyperactivity Disorder (ADD/ADHD) scale is a diagnostic screening and rating scale based on DSM-IV. The validity and reliability of the Turkish version of this inventory was demonstrated by Gunay et al. in 2006 (13). The Adult ADD/ADHD Scale is a Likert type scale which provides 4 sub scores about attention deficit, hyperactivity, impulsivity and problems related to the disorder. Each of the attention deficit, hyperactivity, and impulsivity sections has 9 items to be answered. The problems related to the disorder section contain 30 questions formed according to the accumulated previous clinical experience. The scale also provides a total score which is simply the sum of the four sub scores. A total score less than 20 can be interpreted as mild ADHD symptoms, whereas scores between 20 and 59 can be interpreted as moderate ADHD symptoms, and scores higher than 59 can be interpreted as severe ADHD symptoms (13).

\section{Michigan Alcoholism Screening Test (MAST)}

The MAST is a screening test for evaluating the presence of alcohol use and, if any, the degree of problems related with it. The MAST is a self-report test including 25 questions which have a dichotomy of yes/no type answers. A strong denial as a defense mechanism may be the case in some substance users which may result in lower test scores than expected. In this condition, the evaluation of the test may include clinical judgment. The original form of the MAST was developed by Gibbs in 1983 and the validity and reliability of its Turkish version was demonstrated by Coskunol and colleagues in 1995 (14).

\section{Statistical analysis}

Descriptive statistics were used for demographical variables. In comparison of continuous variables t-test was used when the data was parametric. Additionally, Mann-Whitney $U$ test was also used for continuous variables where appropriate. Categorical variables were compared with the chi-square test. The Pearson analysis was used to evaluate the correlation between the scores of the different scales and other relevant clinical variables. Statistically significance level was accepted as $\mathrm{p}<0.05$.

\section{Results}

The research team explained the study to 136 subjects and asked if they would be willing to participate in the study. Seventy-one of them (52\%), 38 men and 33 women aged between 18 and 50 years, consented to participate and filled-out the study questionnaires as instructed. The mean age of the total group was $26.83 \pm 6.34$ years. Other demographic data of the study group is presented in Table 1. There are no statistically significant gender difference in terms of age, duration of education, economic status, and who the participants are living with. 
More than fifty percent $(53.5 \%)$ of the study group visited a bar/pub more than 3 days in a week. The music preferences of the participants were predominantly in the areas of rock, hard-rock and heavy metal music (Table 2). The majority of participants (76.1\%) listened at random to any music from the 1980s, the 1990s and the last decade. The bar/pub and music preferences of the study group are shown in Table 2.

Almost all of the participants consumed alcohol (93\%). The average duration of alcohol use among the participants was $10.70 \pm 4.68$ years and fifty percent of them were drinking both at home and at the bar/pub, whereas $43.9 \%$ preferred to drink only at the bar/pub. The mean score of the total group in the MAST was $14.13 \pm 8.52$ which means they were experiencing severe problems related to alcohol consumption. In our study group, positive correlations were demonstrated between age, duration of alcohol use, and the MAST scores (age and duration of alcohol use $r=.69 p<0.01$; age and MAST score $r=.363 p<0.01$; duration of alcohol use and the MAST score $r=.322 p<0.05$ ) (Table 3 ).

The results of the psychiatric scales are given in Table 4. According to these results, a quarter of the participants (25.4\%) were at high risk of experiencing a depressive episode when the cut-off score in the BDI was accepted as $\geq 17$. This subgroup with higher BDI scores showed significantly higher scores in all dimensions of the Adult ADD/ADHD scale than the participants who were at a lower risk of depression $(z=-$ $3.8 p=0.001$ for attention deficit; $z=-2.8 p=0.003$ for hyperactivity; $z=-3.02 p=0.002$ for impulsivity; $z=-4.04 p=0.001$ for total score). In our study population, the BDI score was also positively correlated with the attention deficit, hyperactivity, impulsivity, and related feature dimensions of the Adult ADD/ ADHD scale $(r=.461 ; r=.505 ; r=.359 ; r=.360$, for all $p<0.01)$. In addition, more depressed participants showed higher levels of performance fear, total fear, and the total LSAS scores than the less depressed ones $(z=-1.7 p=0.04 ; z=-1.6 p=0.03 ; z=-1.5$ $p=0.04$, respectively).

In our study group, 29 (40.8\%) participants showed mild ADHD symptoms, 41 (57.7\%) participants showed moderate ADHD symptoms, and only 1 (1.4\%) participant showed severe ADHD symptoms. Participants having moderate ADHD symptoms were more depressive than the participants having mild ADHD symptoms $(p<0.0001)$. They showed significantly higher scores in the BDI $1^{\text {st }}, 4^{\text {th }}$, and $9^{\text {th }}$ items (questions that are directly related with depressive mood, anhedonia, and suicidal thoughts in order) as well as in the total score. On the other hand, there were also positive correlations between the attention deficit score and total fear, total avoidance, and the total LSAS scores in the study group $(r=.359 p<0.01 ; r=.332$ $p<0.01 ; r=.358 p<0.01$, respectively).

The mean LSAS total score was $23.8 \pm 18.9$ in the study group. The mean LSAS total fear and total avoidance scores of the study group were $10.0 \pm 9.4$ and $14.1 \pm 11.3$ respectively. We divided the study group into two: (1) participants with significant social anxiety and (2) participants without significant social anxiety. Participants with an LSAS total score equal to, or higher than 30 , were accepted as having significant a significant degree of social anxiety. This was the case for $22(32.3 \%)$ of the participants in the study population. When these two groups were compared, the attention deficit and the MAST scores of group 1 were significantly higher than the scores of group 2 .
Table 1. Demographical variables of the study group $(n=71)$

\begin{tabular}{|c|c|c|}
\hline & Mean & Min-max. \\
\hline Mean age (year) & $26.83 \pm 6.34$ & $18-50$ \\
\hline \multirow[t]{2}{*}{ Duration of education (years) } & 13.18 & 4-19 \\
\hline & $\mathbf{n}$ & $\%$ \\
\hline \multicolumn{3}{|l|}{ Gender } \\
\hline Male & 38 & 53.5 \\
\hline Female & 33 & 46.5 \\
\hline \multicolumn{3}{|l|}{ Marital status } \\
\hline Single & 64 & 93 \\
\hline Married & 5 & 7 \\
\hline \multicolumn{3}{|l|}{ Economic status } \\
\hline Low & 22 & 31 \\
\hline Middle & 32 & 45.1 \\
\hline High & 17 & 23.9 \\
\hline \multicolumn{3}{|l|}{ Occupation } \\
\hline Student & 28 & 39.4 \\
\hline Bar/pub worker & 7 & 9.8 \\
\hline Employed in regular work & 30 & 42.3 \\
\hline Unemployed & 6 & 8.5 \\
\hline \multicolumn{3}{|l|}{ Living (with) } \\
\hline Alone & 16 & 22.5 \\
\hline With friend & 12 & 16.9 \\
\hline With family/parents & 43 & 60.6 \\
\hline
\end{tabular}

Table 2. Music and bar/pub preferences of the study group $(n=71)$

\begin{tabular}{|lcc|}
\hline & $\mathbf{n}$ & $\%$ \\
\hline Music preferences & 38 & 53.5 \\
Rock & 43 & 60.6 \\
Hard-rock & 36 & 50.7 \\
Heavy metal & 16 & 22.5 \\
Trash metal & 7 & 9.9 \\
Death metal & 23 & 32.4 \\
Classical music & 28 & 39.4 \\
Other & & \\
Bar/pub attendance & 12 & 16.9 \\
Every day & 26 & 36.6 \\
More than 3 days in a week & 26 & 36.6 \\
3 days or less in a week & 4 & 5.6 \\
3 days or less in a month & 3 & 4.2 \\
Once every few months & &
\end{tabular}

There were negative correlations between the frequency of bar/pub attendance and performance fear, social fear, and the total fear scores. Additionally, bar/pub attendance was positively correlated with alcohol consumption frequency and 
Table 3. Correlations between different variables of the study group

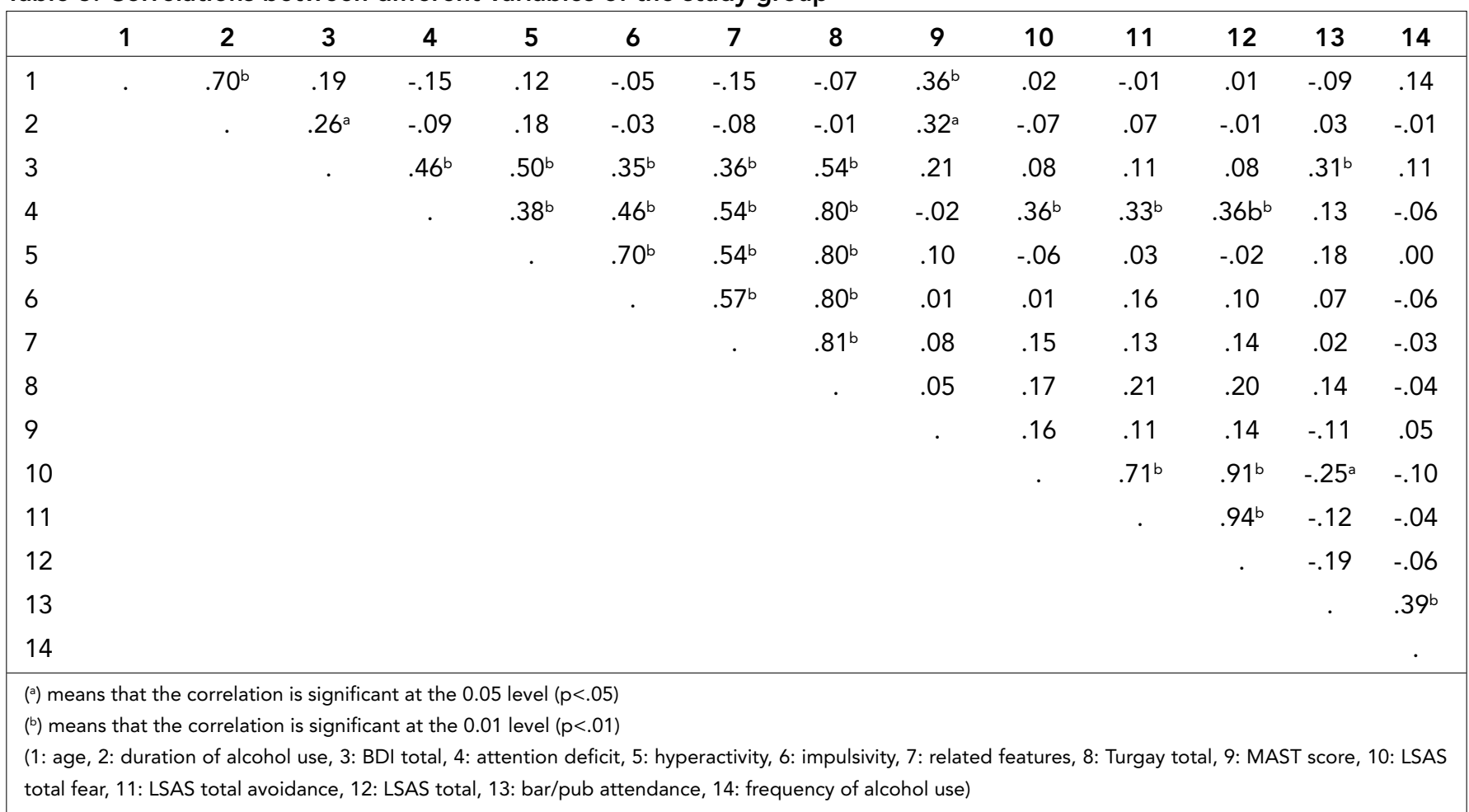

the BDI total score. Our data did not show any correlation or association between alcohol consumption frequency and the LSAS scores.

\section{Discussion}

The main and the novel finding of this study was that heavy metal bar patrons show psychiatric symptoms more than general population. It is important to note that, when invited, only $52 \%$ of the 136 heavy metal bar patrons were willing to participate in the study. Those who declined to participate were not asked why they declined. However, the research team made several observations about this group. The majority of those who declined the invitation to participate in the study were prone to mock and make fun of the study, making comments such as "I don't want to be investigated.", "Do you want to prove that we are all mad/crazy?" The rest of those declining to participate in the study made no additional comments; they just said "No" to the research team. From these observations and the generally low participation rate, we speculate that those who declined participation in the study may have different psychiatric profiles to those of the participants.

The great majority of the participants prefer hard rock and related music types and they consume alcohol. More than half of them visit heavy metal bars more than 3 times in a week. The mean scores of the total group in the MAST revealed that the participants were experiencing severe problems related to alcohol use. As may be expected, positive correlations have been demonstrated between age, duration of alcohol use, and the MAST scores. This finding indicates that in our group of heavy metal bar visitors, the long duration of alcohol use and an older age are associated with problematic alcohol use.
According to our study, roughly one quarter of the patrons of the heavy metal bars were at high risk of depression. The majority of previous studies also showed that heavy metal preference was related to depressive symptoms $(15,16)$ while a recent study from France did not demonstrate such a finding (17). Future studies comparing frequent patrons of heavy metal bars with non-patrons are needed to understand whether being a bar patron has any specific effects on depression risk amongst this population.

One of the striking results is the high ratio of the self-reported ADHD symptoms in the study group. More than half of the subjects reported moderate ADHD symptoms. It is well known that in the general population young adults usually have a tendency to report ADHD symptoms and clinical evaluation is pivotal for ADHD diagnosis. However, we believe that the high ratio of the self-reported ADHD symptoms in our group still deserves further attention. Previous studies of adolescents with a heavy metal music preference have shown that risk taking and sensation seeking behaviors, arrests, drug abuses, recklessness and antisocial behaviors are typically common among this population (18-20). On the other hand, these problematic behaviors are also the complications of ADHD. Thus, a high ratio of ADHD symptoms in this population may be expected and this is not a surprise. We also suggest that these problematic behaviors seen among heavy metal fans, which are mainly centered on impulsivity, might at least in part arise from an unrecognized ADHD diagnosis. The developmental history of heavy metal bar patrons focusing on ADHD symptoms would clarify the issue.

The study findings demonstrated a positive correlation between self-reported depressive symptoms and ADHD symptoms. Indeed, the participants with higher BDI scores had a 
Table 4. Results of the psychiatric scales of the study group $(n=71)$

\begin{tabular}{|lcc|}
\hline & Mean \pm SD & Min-max. \\
\hline BDI 1. item & $0.5 \pm 0.9$ & $0-3$ \\
BDI 4. item & $0.7 \pm 0.8$ & $0-3$ \\
BDI 9. item & $0.3 \pm 0.5$ & $0-3$ \\
BDI total score & $12.2 \pm 8.5$ & $0-63$ \\
Adult ADD/ADHD Scale & & \\
Attention deficit & $6.9 \pm 5.3$ & $0-23$ \\
Hyperactivity & $6.1 \pm 4.4$ & $0-18$ \\
Impulsivity & $3.3 \pm 2.5$ & $0-9$ \\
Related features & $7.0 \pm 3.5$ & $0-17$ \\
Total score & $23.4 \pm 12.7$ & $4-66$ \\
LSAS & & \\
Performance fear & $6.4 \pm 5.7$ & $0-23$ \\
Social fear & $3.6 \pm 4.2$ & $0-14$ \\
Total fear & $10.0 \pm 9.4$ & $0-35$ \\
Performance avoidance & $8.9 \pm 6.9$ & $0-30$ \\
Social avoidance & $5.3 \pm 5.2$ & $0-23$ \\
Total avoidance & $14.2 \pm 11.3$ & $0-49$ \\
LSAS total score & $23.8 \pm 18.9$ & $0-84$ \\
\hline
\end{tabular}

tendency to have higher Adult ADD/ADHD Scale total scores and sub-scores. At the same time, participants with higher ADHD scores also had a tendency to report higher BDI scores. Similar results have been shown in previous clinical studies. These studies showed that adults with ADHD usually had a comorbid depression diagnosis higher than that of the general population $(21,22)$. So, our findings, while supporting previous studies in general population, could be interpreted as showing that this comorbidity may also be common among heavy metal bar attendees.

In the present study, according to the self-report LSAS, one third of the group had significant social anxiety levels, which means one third of the heavy metal bar patrons are likely to have had a social anxiety disorder diagnosis at the time of the study. This is apparently higher than the reported life time prevalence of social anxiety disorder of the general population estimated to be between 9.5 and $16 \%$ (23). The general public notion of heavy metal fans is that they are usually assertive and comfortable in social relations. Supporting this idea, two studies found that heavy metal preference was linked with assertiveness $(15,24)$. However, conversely, our results above-mentioned reveal that heavy metal bar patrons may be at risk of social anxiety disorder. Heavy metal bars are usually very dark places in which it is sometimes hard to recognize people's faces and gestures. The loud music mostly concerns and explores themes of masculinity, independence, personal power, being against the world, easy sexual relations, joy, and perhaps most importantly the brotherhood between the fans of heavy metal music. People inside these bars usually feel that, although the outer world rejects them, they understand each other and they share the same problems and attitudes to life. All of these factors may have a relieving effect on the patrons' levels of social anxiety. Additionally, in heavy metal bars, any rejection met when attempting a social/romantic/ sexual relation, may not be as frustrating as in another public setting because of the darkness, the volume of the music and the level of alcohol consumption amongst of the patrons. Thus, we speculate that for heavy metal fans visiting heavy metal bars, there might be a self medicating effect on social anxiety. In keeping with this hypothesis, in the present study there are negative correlations between the frequency of bar/ pub attendance and certain social anxiety scores. Indeed, this finding was independent of alcohol consumption.

Another interesting finding of the study was the positive correlation between the attention deficit scores of the Adult ADD/ADHD Scale and the social fear and social avoidance scores of the LSAS in the study group. This finding may be interpreted in two ways. It may simply be suggested that subjects with high social anxiety may experience secondary inattentiveness. However, as more than half of the total sample reported both hyperactivity/impulsivity and inattentiveness at the moderate level, which is indicative of ADHD, this argument appears to be less likely. The other speculation about the correlation of self-reported attention deficit and social anxiety symptoms in our sample may be the comorbidity of social anxiety disorder and ADHD/Inattentive type. It is shown that adult $A D H D$ has a high risk of comorbidity with anxiety disorders $(21,22)$ and there is evidence that ADHD/anxiety disorder comorbidity predominantly presents with inattentiveness symptoms $(25,26)$. Notably, a small number of clinical studies have found a link between social anxiety disorder and ADHD (27-29) and a recent study in children found that inattentive type of ADHD presents with difficulties of social assertiveness (30).

The lack of a control group is the main limitation of this study. The comparison of heavy metal bar patrons with visitors of a different social place, i.e., a folk music bar/pub, would yield interesting results. Additionally, comparison of demographical properties of people who did not accept to participate to the study with the study participants would be available if their data were collected. To summarize, according to the self-report questionnaires, our study population of heavy metal bar patrons was found to have high levels of ADHD, social anxiety, and depressive symptoms in comparison with the estimated ratios of the general population. Additionally, various associations were shown between the scales and the subscales of the self-report depression, ADHD, and the social anxiety questionnaires. We suggest that our significant findings of the psychiatric profiles of heavy metal bar patrons in Istanbul warrants that newer and larger sample sized studies be conducted on this particular population in non-Western countries.

\section{Conflict of Interest}

No conflict of interest was declared by the authors.

\section{References}

1. Le'Vine M. Heavy metal Islam. New York: Three Rivers Press; 2008.

2. Baker F, Bor W. Can music preference indicate mental health status in young people? Australas Psychiatry 2008;16:284-8. [CrossRef] 
3. Traeen B, Nordlund S. Visiting public drinking places in Oslo: an application of the theory of planned behavior. Addiction 1993;88:1215-24.

4. Knibbe RA, Drop MJ, Muytens A. Correlates of stages in the progression from everyday drinking to problem drinking. Soc Sci Med 1987;24:463-73. [CrossRef]

5. Traeen B, Rossow I. Social characteristics of urban cafe guests in Norway. Addiction 1994;89:999-1006. [CrossRef]

6. Oldenburg R. The great good place: cafes, coffee shops, community centers, beauty parlors, general stores, bars, hangouts and how they get you through the day. New York: Paragon House; 1989.

7. Whitaker B. Middle East Dispatch: Highway to hell. June 2003. http://www.guardian.co.uk/world/2003/jun/02/worlddispatch. brianwhitaker. Last accessed in 06 January 2011.

8. Warraq I, Ismail R. Islam \& Music, Heavy Metal Islam. November 2008. http://www.newenglishreview.org/custpage.cfm/ frm/27867/sec_id/27867. Last accessed in 06 January 2011.

9. Beck AT. An inventory for measuring depression. Arch Gen Psychiatry 1961;4:561-71.

10. Hisli N. Validity and reliability of Beck Depression Inventory in university students. Psikoloji Dergisi 1989;7:3-13.

11. Mennin DS, Fresco DM, Heimberg RG, Schneier FR, Davies SO, Liebowitz MR. Screening for social anxiety disorder in the clinical setting: using the Liebowitz Social Anxiety Scale. J Anxiety Disord 2002;16:661-73. [CrossRef]

12. Soykan C, Ozguven HD, Gencoz T. Liebowitz Social Anxiety Scale: the Turkish version. Psychol Rep 2003;93:1059-69.

13. Gunay S, Savran C, Aksoy UM, Maner F, Turgay A, Yargıç I. The norm study, transliteral equivalence, validity, reliability of Adult Hyperactivity Scale in Turkish adult population. Psychiatry in Turkey 2006;8:98-107.

14. Coskunol H, Bagdiken I, Sorias S et al. Validity of Michigan Alcoholism Screening Test. Ege Tip Dergisi 1995;34:15-8.

15. Lester D, Whipple M. Music preference, suicidal preoccupation, and personality: comment on Stack and Gundlach's papers. Suicide Life Threat Behav 1996;26:68-70.

16. artin G, Clarke $M$, Pearce $C$. Adolescent suicide: music preference as an indicator of vulnerability. J Am Acad Child Adolesc Psychiatry 1993;32:530-5.

17. Recours R, Aussaguel F, Trujillo N. Metal Music and Mental Health in France. Cult Med Psychiatry 2009;33:473-88. [CrossRef]
18. Swartz KD, Fouts GT. Music preference, personality style, and development of issues of adolescents. J Youth Adolesc 2003;32:205-13.

19. Scheel KR, Westefeld JS. Heavy metal music and adolescent suicidality: an empirical investigation. Adolescence 1999;34:253-73.

20. Took KJ, Weiss DS. The relationship between heavy metal and rap music and adolescent turmoil: Real or artifact? Adolescence 1994;29:613-21.

21. Barkley RA, Brown TE. Unrecognized attention-deficit/hyperactivity disorder in adults presenting with other psychiatric disorders. CNS Spectr 2008;13:977-84.

22. Sobanski E. Psychiatric comorbidity in adults with attention deficit/hyperactivity disorder (ADHD). Eur Arch Psychiatry Clin Neurosci 2006;256:26-31.

23. Ballenger JC, Davidson JR, Lecrubier Y, Nutt DJ, Bobes J, Beidel DC, et al. Consensus statement on social anxiety disorder from the International Consensus Group on Anxiety and Depression. J Clin Psychiatry 1996;59:54-60.

24. Wells A, Hakanen EA. The emotional use of popular music by adolescents. Journalism Quarterly 1991;68:445-54.

25. Jensen PS, Hinshaw SP, Kraemer HC Lenora N, Newcorn JH, Abikoff $\mathrm{HB}$, et al. ADHD comorbidity findings from the MTA study: comparing comorbid subgroups. J Am Acad Child Adolesc Psychiatry 2001;40:147-58. [CrossRef]

26. Newcorn JH, Halperin JM, Jensen PS, Abikoff HB, Arnold LE, Cantwell DP, et al. Symptom profiles in children with ADHD: effects of comorbidity and gender. J Am Acad Child Adolesc Psychiatry 2001;40:137-46. [CrossRef]

27. Mancini C, Van Ameringen M, Oakman JM, Figueiredo D. Childhood attention deficit/hyperactivity disorder in adults with anxiety disorders. Psychol Med 1999;29:515-25. [CrossRef]

28. Kessler RC, Adler L, Barkley R, Biederman J, Conners CK, Demler $\mathrm{O}$ et al. The prevalence and correlates of adult ADHD in the United States: results from the National Comorbidity Survey Replication. Am J Psychiatry 2006;163:716-23. [CrossRef]

29. Adler L.A, Liebowitz M, Kronenberger W, Qiao M, Rubin R, Hollandbeck $\mathrm{M}$ et al. Atomoxetine treatment in adults with attention-deficit/hyperactivity disorder and comorbid social anxiety disorder. Depress Anxiety 2009;26:212-21. [CrossRef]

30. Solanto MV, Pope-Boyd SA, Tryon WW, Stepak B. Social functioning in predominantly inattentive and combined subtypes of children with ADHD. J Attent Disord 2009;13:27-35. [CrossRef] 